Check for updates

Cite this: RSC Adv., 2018, 8, 28625

\title{
Coherent nanoscale cobalt/cobalt oxide heterostructures embedded in porous carbon for the oxygen reduction reaction $\uparrow$
}

\author{
Xue-Cheng Li, ${ }^{a}$ Fa-Shuang She, ${ }^{a}$ Dong Shen, ${ }^{c}$ Chao-Ping Liu, ${ }^{d}$ Li-Hua Chen, (D) ${ }^{a}$ \\ Yu Li, (D) a Zhao Deng, (D) *a Zhen-Hua Chen*b and Hong-En Wang (D) *a
}

Cost-effective and efficient electrocatalysts for the oxygen reduction reaction (ORR) are crucial for fuel cells and metal-air batteries. Herein, we report the facile synthesis of a $\mathrm{Co} / \mathrm{CoO} / \mathrm{CO}_{3} \mathrm{O}_{4}$ heterostructure embedded in a porous carbon matrix by refluxing and annealing. This composite exhibits several structural merits for catalyzing the ORR: (1) the existence of metallic Co and graphitic carbon enhanced the electrical conduction; (2) the porous, loose carbon network facilitated the electrolyte permeation and mass transport; (3) more importantly, the nanosized coherent $\mathrm{CoO} / \mathrm{CO}_{3} \mathrm{O}_{4}$ heterojunctions with structural defects and oxygen vacancies enhanced the charge transport/separation at the interface and adsorption affinity to $\mathrm{O}_{2}$, thus promoting the ORR kinetics and lowering the reaction barrier. Consequently, the composite electrode manifests high electrocatalytic activity, attaining a current density of $6.7 \mathrm{~mA} \mathrm{~cm}{ }^{-2}$ at $-0.8 \mathrm{~V}$ (vs. $\mathrm{Ag} / \mathrm{AgCl}$ ), which is superior to pure CoO nanoparticles (4.7 mA $\mathrm{cm}^{-2}$ ), and has good methanol tolerance. The present strategy based on heterostructure and vacancy engineering may pave the way for the exploration of more advanced, low-cost electrocatalysts for electrochemical reduction and evolution processes.

Received 18th May 2018

Accepted 6th August 2018

DOI: $10.1039 / \mathrm{c} 8 \mathrm{ra04256j}$

rsc.li/rsc-advances morphology, microstructures and rich active sites. Nonetheless, Co-based nanomaterials still have some disadvantages, such as easy aggregation and low electronic conductivity, leading to decreased active surface area and poor charge transfer/ transport kinetics during electrochemical redox reactions. Encapsulating Co or cobalt oxides into porous carbon frameworks can in principle boost the electrical conduction and form strong interfacial electron coupling, resulting in enhanced electrocatalytic activity and stability. ${ }^{28,29}$ In addition, intentional and rational design and fabrication of $\mathrm{Co} / \mathrm{CoO}_{x}$ heterojunctions could potentially further improve the interfacial charge transfer and electron transport, featuring better electrocatalytic property than single $\mathrm{Co} / \mathrm{CoO}_{x}$ components. ${ }^{30-32}$ However, the effective synthesis of such composite materials that can combine all structural advantages remains challenging and deserves further study.

In this paper, we report the designed synthesis of $\mathrm{Co} / \mathrm{CoO} /$ $\mathrm{Co}_{3} \mathrm{O}_{4}$ heterostructure (denoted as $\mathrm{CoO}_{x}$ ) embedded in porous carbon matrix as efficient catalyst for ORR. The composite was obtained by a simple refluxing followed by annealing treatment. The synergic coupling of coherent $\mathrm{CoO} / \mathrm{Co}_{3} \mathrm{O}_{4}$ heterojunctions and presence of metallic Co and conductive amorphous carbon enable the material a high and stable electrocatalytic performance. Our work presented herein can provide new insights into the rational design and synthesis of new heterostructuretype transition metal compounds for electrochemical energy conversion and storage applications. 


\section{Experimental section}

All the chemicals were of analytical pure grade and used as received without further purification.

\section{Material synthesis}

\section{Synthesis of CoO nanoparticles}

Pure $\mathrm{CoO}$ nanoparticles were prepared by a mild refluxing process in oleylamine under Ar protection referring our previous work ${ }^{33}$ with little modifications. In a typical procedure, a mixture of $\mathrm{Co}$ (acetylacetonate $)_{3}(1.6 \mathrm{mmol})$ and oleylamine (80 $\mathrm{mmol}$ ) was heated to $135^{\circ} \mathrm{C}$ and maintained at this temperature for 90 min with magnetic stirring. The resulting solution was then heated to $200{ }^{\circ} \mathrm{C}$ within $5 \mathrm{~min}$ and refluxed at this temperature for another $60 \mathrm{~min}$, finally cooled to room temperature naturally. During this process, the $\mathrm{Co}$ (acetylacetonate $)_{3}$ was decomposed into nanosized $\mathrm{CoO}$ in situ capped with oleylamine. After reaction, excess ethanol was added to the resulting mixture to precipitate the brown product. The resultant $\mathrm{CoO}$ nanoparticles were thoroughly washed with ethanol to remove the residual oleylamine adsorbed on their surface, and were dried under Ar protection before being dispersed in hexane again for further use.

\section{Synthesis of $\mathrm{CoO}_{x} / \mathrm{C}$ composite}

$\mathrm{CoO}_{x} / \mathrm{C}$ composite sample was prepared by annealing the refluxed $\mathrm{CoO}$ product before removing oleylamine (without rinsing) in a tube furnace at setting temperatures $\left(400-800{ }^{\circ} \mathrm{C}\right)$ for $2 \mathrm{~h}$ under purged Ar. For simplicity, the samples obtained after thermal treatment at $400{ }^{\circ} \mathrm{C}, 600{ }^{\circ} \mathrm{C}$ and $800{ }^{\circ} \mathrm{C}$ were donated as $\mathrm{CoO}_{x}-400, \mathrm{CoO}_{x}-600$ and $\mathrm{CoO}_{x}-800$, respectively.

\section{Characterizations}

X-ray diffraction (XRD) patterns were recorded on a Bruker diffractometer with $\mathrm{Cu} \mathrm{K} \alpha$ radiation $(\lambda=1.54056 \AA)$ at $40 \mathrm{kV}$ $\mathrm{mA}^{-1}$. The morphology of the samples was observed by a scanning electron microscope (SEM, Hitachi S-4800) equipped with an energy-dispersive X-ray (EDX) analyzer. Transmission electron microscopy (TEM) and high-resolution TEM (HRTEM) micrographs were acquired on a JEOL JEM-2100F microscope at $200 \mathrm{kV}$. Raman measurement was performed at room temperature by an Invia Raman microscope (Renishaw, UK) using $633 \mathrm{~nm}$ excitation wavelength. The electronic states and surface composition of the sample were analyzed by X-ray photoelectron spectroscope (XPS, Thermo fisher, Alpha). The binding energies (BE) for the sample were calibrated using $\mathrm{C}$ 1s peak from a carbon tape at $284.8 \mathrm{eV}$.

\section{Electrochemical tests}

Electrochemical measurements were recorded on a CHI 660D electrochemical workstation in a three-electrode system at room temperature. The glassy carbon electrode with a diameter of 5 $\mathrm{mm}$, Pt foil and $\mathrm{Ag} / \mathrm{AgCl}$ were used as working electrode, counter electrode and reference electrode, respectively. The electrochemical experiments were carried out in an $\mathrm{O}_{2}$-saturated $0.1 \mathrm{M} \mathrm{KOH}$ aqueous solution electrolyte. To prepare the working electrode, $5 \mathrm{mg}$ sample and $15 \mu \mathrm{L}$ Nafion solution (5 wt\%) was thoroughly dispersed in $1 \mathrm{~mL}$ water and isopropanol (volume ratio of $3: 1$ ) by sonication for $30 \mathrm{~min}$ to form a homogeneous ink. Then $4 \mu \mathrm{L}$ of catalyst ink (containing $\sim 20$ $\mu \mathrm{g}$ catalyst) was cast on the surface of the glassy carbon electrode and dried in air. The rotating-disk electrode (RDE) measurements were carried out at a sweep rate of $5 \mathrm{mV} \mathrm{s}^{-1}$ with varied rotation speeds from 400 to $2025 \mathrm{rpm}$. To evaluate the methanol resistance capability of the electrode, cyclic voltammetry (CV) sweep was recorded in an $\mathrm{O}_{2}$-saturated $0.1 \mathrm{M} \mathrm{KOH}$ electrolyte with and without addition of $3 \mathrm{M}$ methanol for comparison.

\section{Results and discussion}

The crystal structure of the as-prepared samples was first studied by XRD analysis. As shown in Fig. 1, the crystallinity of the samples increases along with the increase of annealing temperature as reflected by sharp diffraction peaks. All the three samples contain cubic CoO (space group Fm3m, JCPDS 01$1227)^{30}$ and cubic metallic Co (space group $F m 3 m$, JCPDS 150806) ${ }_{17}^{17}$ suggesting the $\mathrm{CoO}$ can be easily reduced to Co species by surface residual oleylamine under inert atmosphere. In addition, two additional peaks (marked by “*” and "\#”) are noted in $\mathrm{CoO}_{x}-600$ and cannot be indexed to known cobaltbased compounds, which may be related to the formation of some unknown intermediate products. Another interesting feature is that cubic $\mathrm{Co}_{3} \mathrm{O}_{4}$ (space group $\mathrm{Fd3m}$, JCPDS 01$1152)^{20 a}$ can also exist in the $\mathrm{CoO}_{x}-800$ and $\mathrm{CoO}_{x}-600$ sample because at high annealing temperatures some exposed Co species formed by the removal of most adjacent carbon species (in form of $\mathrm{CO}$ or $\mathrm{CO}_{2}$ ) may be re-oxidized into $\mathrm{Co}_{3} \mathrm{O}_{4} \cdot{ }^{20 b}$ However, from Fig. 1 the strong diffraction peak of (311) plane (red) for $\mathrm{Co}_{3} \mathrm{O}_{4}$ at $2 \theta=\sim 37^{\circ}$ (Note that it may also be (111) plane (black) for $\mathrm{CoO}$ ) has a much weaker intensity compared to the strong diffraction peak of (111) plane (blue) for Co, suggesting the low content of $\mathrm{Co}_{3} \mathrm{O}_{4}(\mathrm{CoO})$ relative to $\mathrm{Co}$ species in the

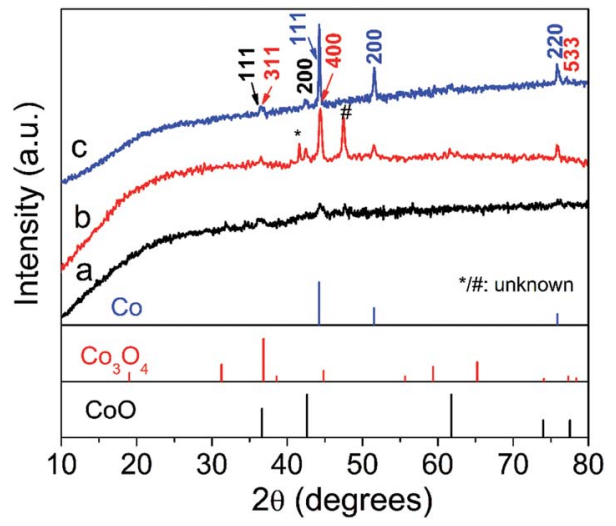

Fig. 1 XRD patterns of (a) $\mathrm{CoO}_{x}-400$, (b) $\mathrm{CoO}_{x}-600$ and (c) $\mathrm{CoO}_{x}-800$ samples. 


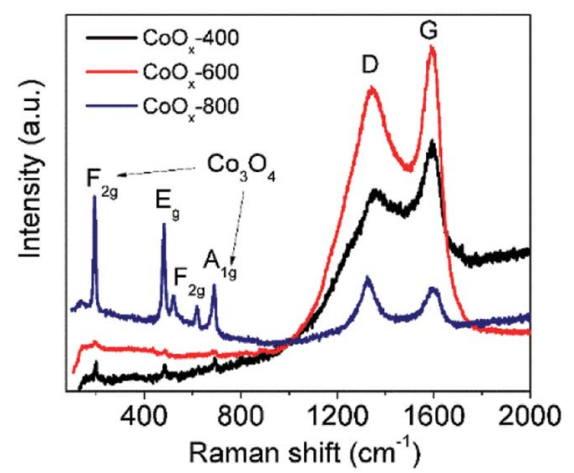

Fig. 2 Raman spectra of the samples prepared by refluxing and annealing for $2 \mathrm{~h}$ in $\mathrm{Ar}$ at $400{ }^{\circ} \mathrm{C}\left(\mathrm{CoO}_{x}-400\right), 600{ }^{\circ} \mathrm{C}\left(\mathrm{CoO}_{x}-600\right)$ and $800{ }^{\circ} \mathrm{C}\left(\mathrm{CoO}_{x}-800\right)$.

composite. However, the low content of $\mathrm{Co}_{3} \mathrm{O}_{4}$ and the superimposition of major diffraction peaks position between $\mathrm{Co}_{3} \mathrm{O}_{4}$ and $\mathrm{CoO}$ make the identification of $\mathrm{Co}_{3} \mathrm{O}_{4}$ difficult and challenging. For this, its presence has been further confirmed by the existence of $\mathrm{Co}^{3+}$ species in XPS and HRTEM analyses in the following.

The crystal and carbon structure of the $\mathrm{CoO}_{x}$ was further analyzed by Raman spectra, as shown in Fig. 2. The noticeable peaks can be indexed to the $\mathrm{F}_{2 \mathrm{~g}}\left(196.5 \mathrm{~cm}^{-1}\right), \mathrm{E}_{\mathrm{g}}\left(480.9 \mathrm{~cm}^{-1}\right)$, $\mathrm{F}_{2 \mathrm{~g}}\left(517.7\right.$ and $\left.617.7 \mathrm{~cm}^{-1}\right)$ and $\mathrm{A}_{1 \mathrm{~g}}\left(686.2 \mathrm{~cm}^{-1}\right)$ modes of $\mathrm{Co}_{3} \mathrm{O}_{4},{ }^{34}$ further evidencing the existence of $\mathrm{Co}_{3} \mathrm{O}_{4}$ phase localized mainly at surface. Compared to literature, ${ }^{34}$ all the Raman peaks for $\mathrm{Co}_{3} \mathrm{O}_{4}$ in the composite shifted to lower wavenumbers possibly caused by the presence of oxygen vacancies $^{35,36}$ as further discussed in the XPS analyses in the following. Another two strong Raman peaks centering around $1357 \mathrm{~cm}^{-1}$ and $1605 \mathrm{~cm}^{-1}$ can be assigned to the D-band (vibrations of $\mathrm{sp}^{3}$-hybridized carbon atoms with dangling bonds) and G-band ( $\mathrm{sp}^{2}$-bonded carbon atoms) of graphitic carbon, respectively, ${ }^{37,38}$ formed by carbonization of residual oleylamine. It is found that the intensity of $\mathrm{D}$ and $\mathrm{G}$ bands of the products increased first with increasing temperature, while it decreased with further increasing temperature. Generally, the D and $\mathrm{G}$ bands represent the degree of graphitization and content of the graphitized carbon in the composite. Therefore, the enhancement of $\mathrm{D}$ and $\mathrm{G}$ band intensity of $\mathrm{CoO}_{x}-600$ relative to $\mathrm{CoO}_{x}-400$ can signify an increase of the graphitized carbon in the composite because the annealing temperature of $400{ }^{\circ} \mathrm{C}$ is still low for carbonization process. This can also be reflected in the following SEM characterization, which reveals that the morphology of $\mathrm{CoO}_{x}-400$ doesn't alter much compared to CoO. Instead, the $\mathrm{CoO}_{x}-600$ product contains some $1 \mathrm{D}$ nanostructures (probably carbon nanotubes) that are formed by carbonization catalyzed by the metallic Co species. However, further increasing annealing temperature to $800{ }^{\circ} \mathrm{C}$, the carbon species can further reduce $\mathrm{CoO}$ into $\mathrm{Co}$; meantime, some carbon substances are converted into $\mathrm{CO}$ or $\mathrm{CO}_{2}$ and thus consumed, giving rise to reduced total graphitized carbon in the composite and a lowered D and G band intensity in Raman as well. In addition, the slight increase of intensity for $I_{\mathrm{D}}$ relative to $I_{\mathrm{G}}$ in $\mathrm{CoO}_{x}-800$ compared to $\mathrm{CoO}_{x}-400$ and $\mathrm{CoO}_{x}-600$ can be mainly ascribed to the possible presence of some strain at the $\mathrm{Co} / \mathrm{CoO} / \mathrm{Co}_{3} \mathrm{O}_{4}$ and carbon interface in the composite as revealed by the fusion of most nanoparticles together in the $\mathrm{CoO}_{x}-800$ product from SEM observation.

The surface valence electronic states and element composition in the $\mathrm{CoO}_{x}-800$ sample were investigated by XPS. The survey XPS spectrum in Fig. 3a validates the existence of Co, O and $\mathrm{C}$ elements in the sample. The deconvolution of Co $2 \mathrm{p}$ core level XPS reveals the presence of three pairs of peaks (Fig. 3b). The first pair of peaks with lower binding energies (BE) centered at $779.4 \mathrm{eV}$ and $794.4 \mathrm{eV}$ can be ascribed to Co $2 \mathrm{p}_{3 / 2}$ and Co $2 \mathrm{p}_{1 / 2}$ of metallic Co. ${ }^{26}$ Another pair of peaks with BE at 780.4 and $795.9 \mathrm{eV}$ can be assigned to the $2 \mathrm{p}_{3 / 2}$ and $2 \mathrm{p}_{1 / 2}$ of $\mathrm{Co}^{3+}$ in $\mathrm{Co}_{3} \mathrm{O}_{4}{ }^{20}$ The two bands at higher $\mathrm{BE}$ of 781.8 and $797.3 \mathrm{eV}$ correspond to the $2 \mathrm{p}_{3 / 2}$ and $2 \mathrm{p}_{1 / 2}$ of $\mathrm{Co}^{2+}$ in $\mathrm{CoO} / \mathrm{Co}_{3} \mathrm{O}_{4} \cdot{ }^{20,39}$ Additionally, two broad bands centering at $784 \mathrm{eV}$ and $803 \mathrm{eV}$ are noted for shakeup satellite peaks of $\mathrm{Co}^{2+}$ and $\mathrm{Co}^{3+} \cdot{ }^{39} \mathrm{~A}$ rough estimation from the area ratio of $\mathrm{Co}^{3+}$ (for $\mathrm{Co}_{3} \mathrm{O}_{4}$ ) to $\mathrm{Co}^{0}$ in metallic Co species reveals the content of $\mathrm{Co}_{3} \mathrm{O}_{4}$ is comparable to that of Co on the surface. This result does not violate the XRD result because XPS is a surface-sensitive characterization. On the contrary, these XPS data further support that the $\mathrm{Co}_{3} \mathrm{O}_{4}$ species mainly localize on the composite surface and prevent further oxidation of Co underneath. Fig. 3c depicts the O 1s XPS spectrum, which can be deconvoluted into three bands: O-Co bond $(529.6 \mathrm{eV}),{ }^{39}$ oxygen vacancy $\left(V_{\mathrm{o}}, 531 \mathrm{eV}\right),{ }^{35}$ and $\mathrm{O}-\mathrm{C}$ bond $(532.1 \mathrm{eV}) .{ }^{40}$ Note that the $V_{\mathrm{o}}$ can be ascribed to the incomplete reduction from $\mathrm{CoO}$ to $\mathrm{Co}$ during carbonization of organics. The deconvolution of $\mathrm{C} 1 \mathrm{~s}$ spectrum in Fig. 3d indicates the presence of $\mathrm{C}-\mathrm{C} / \mathrm{C}=\mathrm{C}$ bonds for graphite carbon $(284.4 \mathrm{eV})$, $\mathrm{C}-\mathrm{O}$ bond $(285.8 \mathrm{eV})$ and $\mathrm{C}=\mathrm{O}$ bond $(288 \mathrm{eV})$ for surface functional groups. ${ }^{\mathbf{4 0 , 4 1}}$

The surface morphologies of the prepared $\mathrm{CoO}_{x}$ samples were first observed by SEM. In Fig. 4a, the CoO sample synthesized by refluxing alone contains spherical nanoparticles with sizes of $20-30 \mathrm{~nm}$, which is in consistent with previous work. ${ }^{33}$ After annealing the refluxed $\mathrm{CoO}$ at $400{ }^{\circ} \mathrm{C}$ for $2 \mathrm{~h}$ in $\mathrm{Ar}$, the resultant sample $\left(\mathrm{CoO}_{x}-400\right)$ is composed of some larger particles with sizes of 40-60 $\mathrm{nm}$ that are fused together (Fig. 4b). In $\mathrm{CoO}_{x}-600$ sample, some large aggregates $(\sim 400 \mathrm{~nm})$ and copious 1D carbon nanostructures are observed (marked by white arrows). The formation of such 1D carbon nanomaterials can be probably due to the catalytic effect of Co species. That is, metallic Co formed during the carbonized process in turn catalyzed the production of 1D nanostructured carbon. ${ }^{42}$ For the $\mathrm{CoO}_{x}-800$ sample, it mainly comprises larger aggregates with few 1D carbon nanostructures (Fig. 4d). The formation of such aggregates suggests the fusion of most $\mathrm{CoO}_{x}$ particles mediated by carbon species to minimize the total surface energy of the whole system during annealing process. Fig. 5 shows the SEM micrograph of the $\mathrm{CoO}_{x}-800$ sample and corresponding EDX map of $\mathrm{C}, \mathrm{O}$ and $\mathrm{Co}$ elements, proving their relatively uniform distribution.

Fig. 6 presents the TEM and HRTEM micrographs of the $\mathrm{CoO}_{x}-800$ sample. The TEM in Fig. 6a shows several $\mathrm{CoO}_{x}$ particles with sizes of $\sim 100 \mathrm{~nm}$ that are embedded in a porous carbon matrix. In addition, few $\mathrm{CoO}_{x}$ particles have exposed 

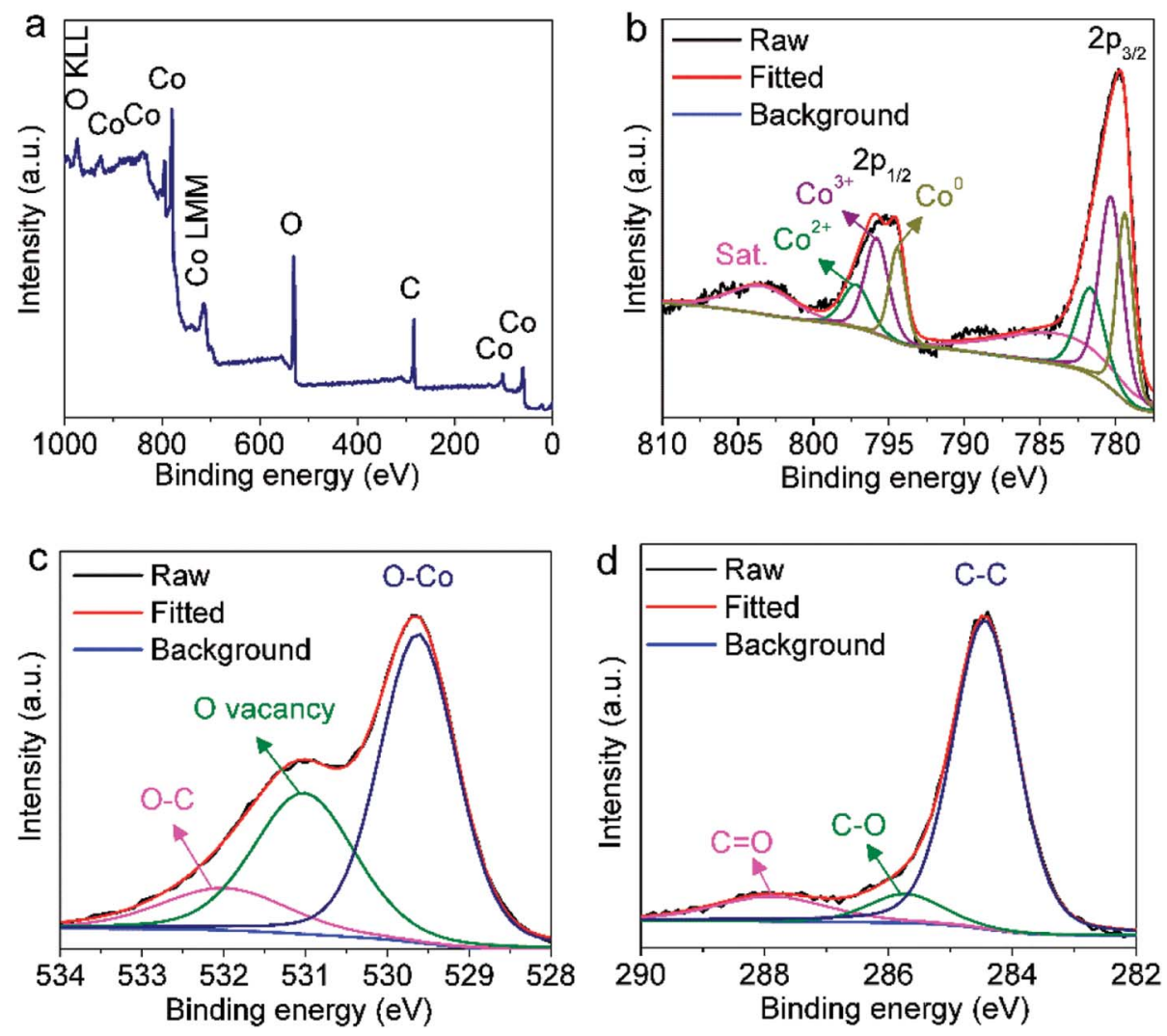

Fig. 3 (a) XPS survey spectrum and high-resolution XPS spectra of (b) Co $2 p$, (c) $\bigcirc 1 s$ and (d) $C 1$ s core levels in $\mathrm{CoO}_{x}-800$ sample.

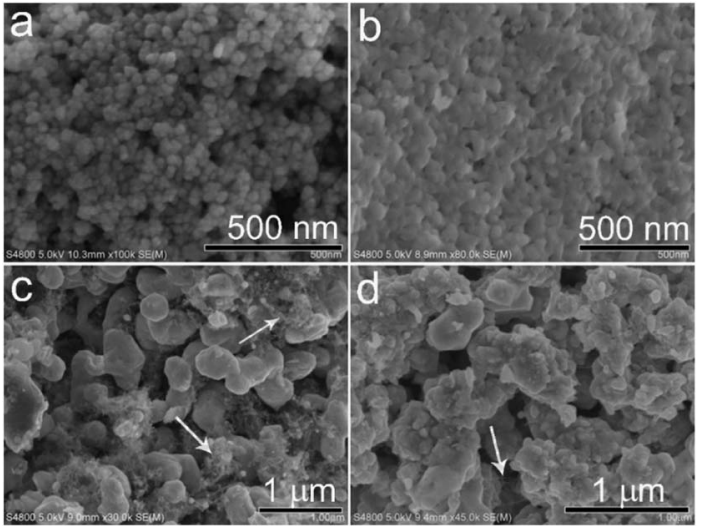

Fig. 4 SEM images of the samples synthesized by refluxing (a), and annealing in $\mathrm{Ar}$ at $400{ }^{\circ} \mathrm{C}\left(\mathrm{CoO}_{x}-400\right)(\mathrm{b}), 600^{\circ} \mathrm{C}\left(\mathrm{CoO}_{x}-600\right)$ (c) and $800{ }^{\circ} \mathrm{C}\left(\mathrm{CoO}_{x}-800\right)(\mathrm{d})$, respectively.

surface (without coating with carbon layer) possibly due to the complete removal of organics surrounding them. In Fig. 6b, some ring-like carbon nanostructures are observed as indicated by black arrows. The formation of such carbon nanostructure can be ascribed to the carbonization of organics into carbon nanotubes catalyzed by Co species, which agrees with the SEM result (Fig. 4d). Fig. 6c displays the HRTEM micrograph of a portion of a single $\mathrm{CoO}_{x}$ particle capped by thin carbon layers $(\sim 5 \mathrm{~nm}$ thick as marked by black arrows). Fast Fourier
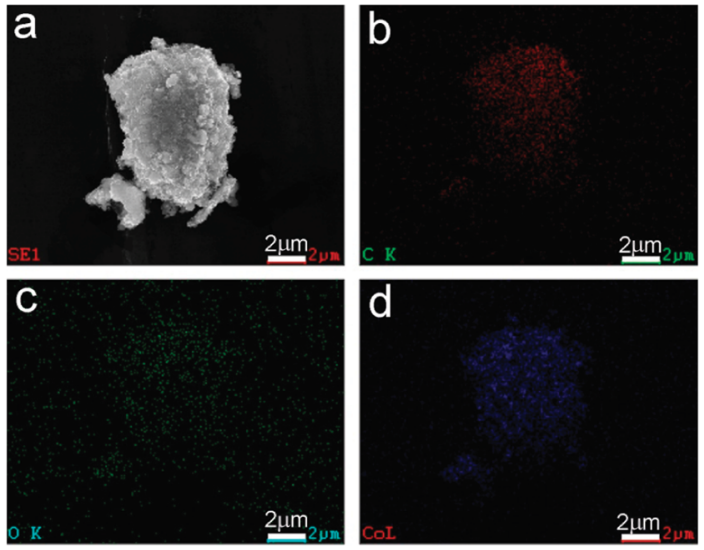

Fig. 5 (a) SEM image and EDX mappings of (b) $C$, (c) O, and (d) Co elements in the $\mathrm{CoO}_{x}-800$ sample, evidencing their relatively uniform distribution.

Transform (FFT) image in Fig. 6d taken from area 1 in Fig. 6c (marked by white square at the bottom left) clearly reveals the coexistence of cubic $\mathrm{CoO}$ (JCPDS 01-1227) and $\mathrm{Co}_{3} \mathrm{O}_{4}$ (JCPDS 011152) phases, suggesting the formation of nanoscale coherent $\mathrm{CoO} / \mathrm{Co}_{3} \mathrm{O}_{4}$ heterojunctions in the composite. The inverse FFT (IFFT) image in Fig. 6e obtained from (111) and (11-1) planes in Fig. 6d (labelled by yellow color) after applying a filter depicts a $2 \mathrm{D}$ lattice image of $\mathrm{CoO}$ with some distortions, suggesting the presence of some defects (e.g., edge dislocations and oxygen 
vacancy). ${ }^{35}$ The HRTEM image of the area 2 in Fig. 6c (white square on the top right) and corresponding FFT image (Fig. 6f) further confirm the coexistence of $\mathrm{CoO} / \mathrm{Co}_{3} \mathrm{O}_{4}$ phases with a sharp interface (marked by the black dotted line in Fig. 6c). Note that both domains 1 and 2 in Fig. $6 \mathrm{c}$ contain $\mathrm{Co}_{3} \mathrm{O}_{4}$ phase. Careful inspection indicates that these two domains are both located at the (thin) edge regions with incomplete carbon encapsulation, meaning that $\mathrm{Co}_{3} \mathrm{O}_{4}$ can be formed by the reoxidation of the exposed Co species upon exposure to air.

Based on the above characterizations, we deduce that during the carbonization process some newly formed Co species can migrate, fuse and segregate together with exposed surface accompanied by the removal of some carbonaceous substances (CO, $\mathrm{CO}_{2}$ etc.). The exposed Co surface can then be easily reoxidized into $\mathrm{Co}_{3} \mathrm{O}_{4}$ upon exposure to air. Once oxidation, the newly formed $\mathrm{Co}_{3} \mathrm{O}_{4}$ layer as well as the carbon encapsulation can prevent the complete oxidation of all Co species. Therefore, a composite of $\mathrm{CoO} / \mathrm{Co} / \mathrm{Co}_{3} \mathrm{O}_{4}$ with carbon was produced in the end.

It should be stressed that the finding of coexistence of $\mathrm{Co}_{3} \mathrm{O}_{4}$ at surface due to spontaneous oxidation of Co is important for catalysis-related research because most of these reactions are surface-involved/sensitive process involving $\mathrm{O}_{2}$. Therefore, the surface composition, (micro) structure and chemical states of Co and Co-based compounds will undoubted exert a crucial role on the catalytic property of this class of electrocatalyst materials.

Fig. 7a shows the ORR polarization curves of $\mathrm{CoO}, \mathrm{CoO}_{x^{-}}$ $400, \mathrm{CoO}_{x}-600$ and $\mathrm{CoO}_{x}-800$ obtained at a rotation rate of $1600 \mathrm{rpm}$ in an $\mathrm{O}_{2}$-saturated $0.1 \mathrm{M} \mathrm{KOH}$ electrolyte. It is clear that $\mathrm{CoO}_{x}-800$ electrode exhibits a higher current of $6.7 \mathrm{~mA}$

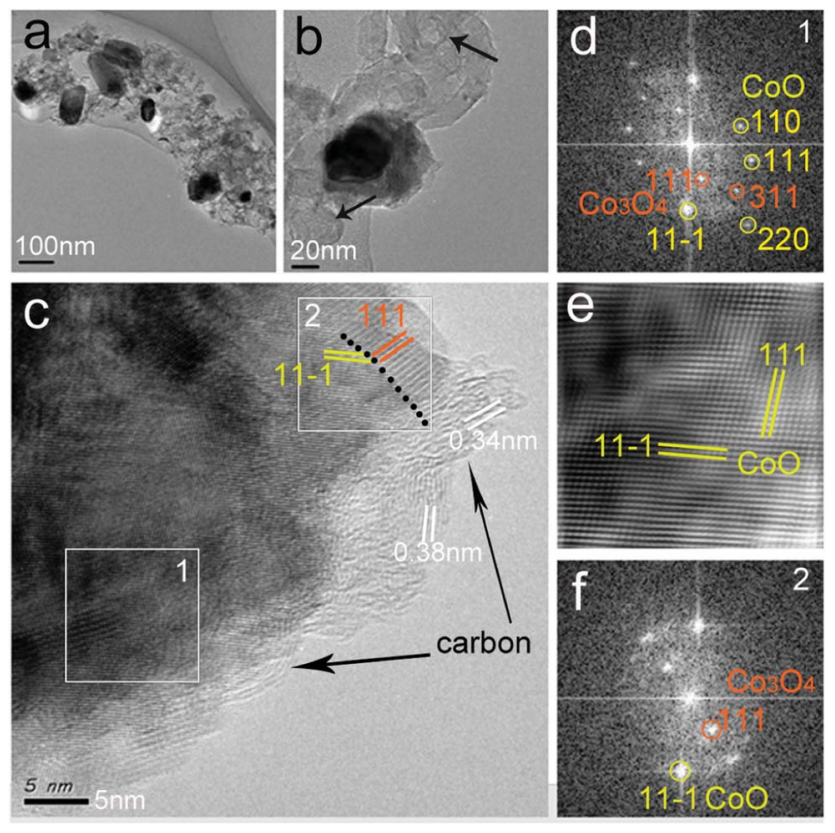

Fig. 6 (a and b) TEM images; (c) HRTEM micrographs; ( $d$ and f) fast Fourier transform (FFT) patterns taken from square areas 1 and 2 in (c), respectively; (e) inverse FFT image derived from (111) and (11-1) planes of $\mathrm{CoO}$ in (d) of the $\mathrm{CoO}_{x}-800$ sample. $\mathrm{cm}^{-2}$ at $-0.8 \mathrm{~V}$, which is superior to that of $\mathrm{CoO}\left(4.7 \mathrm{~mA} \mathrm{~cm}^{-2}\right)$, $\mathrm{CoO}_{x}-400\left(5.9 \mathrm{~mA} \mathrm{~cm}{ }^{-2}\right)$, and $\mathrm{CoO}_{x}-600\left(6.2 \mathrm{~mA} \mathrm{~cm}^{-2}\right)$ electrodes as well as the electrodes comprised of commercial $\mathrm{Co}_{3} \mathrm{O}_{4}\left(2.25 \mathrm{~mA} \mathrm{~cm}^{-2}\right)$ and $\mathrm{CoO}\left(1.8 \mathrm{~mA} \mathrm{~cm}^{-2}\right)$ nanoparticles (Fig. $\mathrm{S} 1 \dagger$ ) at the same applied potential. Besides, $\mathrm{CoO}_{x}-800$ sample shows a halfwave potential of $c a .-0.28 \mathrm{~V}$ ( $v s . \mathrm{Ag} / \mathrm{AgCl})$, which is $50 \mathrm{mV}$ more positive than that of pristine $\mathrm{CoO}(-0.33$ V). These results suggest that the $\mathrm{CoO}_{x}-800$ material exhibits better electrocatalytic activity toward ORR process. Note that our $\mathrm{CoO}_{x}-800$ electrode also exhibits better or comparable electrocatalytic activity to that of some other Co-based compounds in previous literatures, such as $\mathrm{Co} / \mathrm{CoO}$ nanoparticles assembled on graphene, ${ }^{23} \mathrm{Co} / \mathrm{CoO}$ nanoparticles immobilized on Co-N doped carbon, ${ }^{25} \mathrm{Co}-\mathrm{N}-\mathrm{C}$ framework, ${ }^{43}$ and N-doped carbon nanofibers encapsulating Co nanoparticles. ${ }^{\mathbf{1 7}}$

The reaction kinetics of the $\mathrm{CoO}_{x}-800$ electrode were further studied by rotating-disk electrode (RDE) voltammetry tests. Linear sweep voltammetry (LSV) profiles in an $\mathrm{O}_{2}$-saturated $0.1 \mathrm{M} \mathrm{KOH}$ electrolyte show that the current response increases with increasing rotation rates from 400 to $2025 \mathrm{rpm}$ (Fig. 7b). The onset potential of $\mathrm{CoO}_{x}-800$ electrode for the ORR process initiates at ca. $-0.10 \mathrm{~V}$. The corresponding Koutecky-Levich (KL) plots in Fig. 7c further exhibit good linearity. The slopes remain approximately constant over the potential range from -0.10 to $-0.50 \mathrm{~V}$, suggesting a similar electron-transfer number per $\mathrm{O}_{2}$ molecule involved in ORR within the scanned potential range. Linearity and parallelism of the plots usually imply firstorder reaction kinetics with respect to the concentration of dissolved $\mathrm{O}_{2}$. The kinetic parameters have been further analyzed using $\mathrm{K}-\mathrm{L}$ equations following eqn (1)-(3):

$$
\begin{gathered}
\frac{1}{J}=\frac{1}{J_{\mathrm{L}}}+\frac{1}{J_{\mathrm{K}}}=\frac{1}{B \omega^{1 / 2}}+\frac{1}{J_{\mathrm{K}}} \\
B=0.62 n F C_{0} D_{0}^{2 / 3} v^{-1 / 6} \\
J_{\mathrm{k}}=n F k C_{0}
\end{gathered}
$$

where $J$ is measured current density, $J_{\mathrm{K}}$ and $J_{\mathrm{L}}$ are kinetic- and diffusion-limiting current densities respectively, $\omega$ is angular velocity of the disk ( $\omega=2 N \pi, N$ is linear rotation speed), $n$ is electron transfer number involved in the reduction of one $\mathrm{O}_{2}$ molecule, $F$ is Faraday constant (96 $485 \mathrm{C} \mathrm{mol}^{-1}$ ), $C_{0}$ is bulk concentration of $\mathrm{O}_{2}$ dissolved in the electrolyte $(1.2 \times$ $\left.10^{-3} \mathrm{~mol} \mathrm{~L}^{-1}\right), D_{0}$ is diffusion coefficient of $\mathrm{O}_{2}$ in electrolyte $\left(1.9 \times 10^{-5} \mathrm{~cm}^{2} \mathrm{~s}^{-1}\right), v$ is kinetic viscosity of the electrode $(0.1$ $\mathrm{m}^{2} \mathrm{~s}^{-1}$ ), and $k$ is electron-transfer rate constant. According to eqn (1) and (2), $n$ and $J_{\mathrm{K}}$ can be obtained from the slope and intercept of the $\mathrm{K}-\mathrm{L}$ plots, respectively.

The average electron transfer numbers of $\mathrm{CoO}_{x}-800$ sample were calculated to be $\sim 3.9$ at -0.3 to $-0.5 \mathrm{~V}$ (vs. $\mathrm{Ag} /$ $\mathrm{AgCl}$ ), indicating that $\mathrm{CoO}_{x}-800$ can efficiently catalyze ORR process via a four-electron pathway. In addition, the electrochemical stability and methanol tolerance capability are 

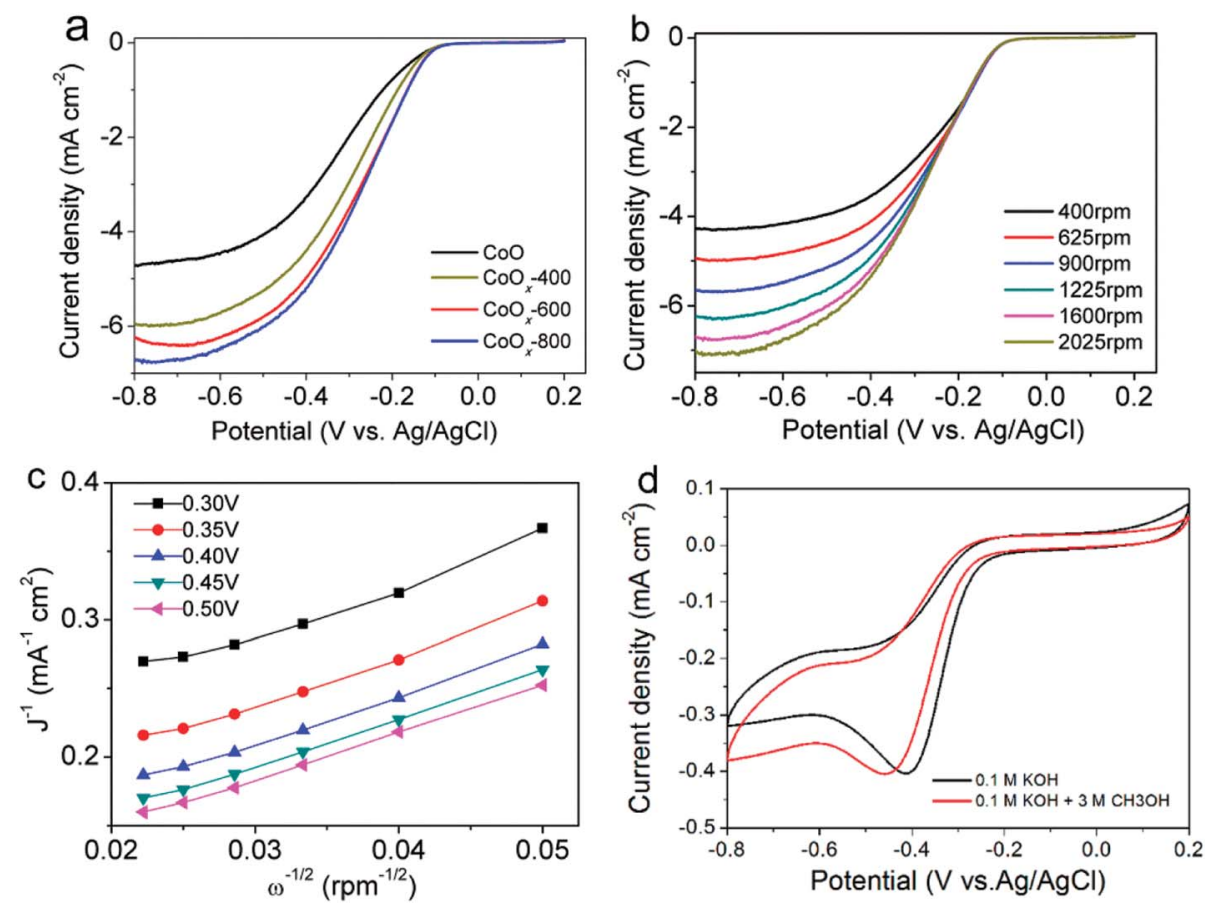

Fig. 7 Electrochemical oxygen reduction on as-prepared $\mathrm{CoO}_{x}$ samples. (a) $\mathrm{LSV}$ curves of $\mathrm{CoO}, \mathrm{CoO}-400, \mathrm{CoO}_{x}-600$ and $\mathrm{CoO}$ - 800 samples with a sweep rate of $5 \mathrm{mV} \mathrm{s}^{-1}$ at $1600 \mathrm{rpm}$; (b) LSV curves of $\mathrm{CoO}_{x}-800$ electrode at a scan rate of $5 \mathrm{mV} \mathrm{s}^{-1}$ under various rotation rates; (c) corresponding Koutecky-Levich plots of $\mathrm{CoO}_{x}-800$ electrode; (d) CV curves of $\mathrm{CoO}_{x}-800$ electrodes with (red curve) and without (black curve) adding $3 \mathrm{M}$ methanol into the $\mathrm{O}_{2}$-saturated $0.1 \mathrm{M} \mathrm{KOH}$ electrolyte.

also important performance indicators for ORR electrocatalysts. As seen from Fig. 7d, it is noted that the two curves have comparable peak current $\left.(\sim 0.4 \mathrm{~mA} \mathrm{~cm})^{-2}\right)$ during cathodic process albeit with the more negative potential for the one with addition of methanol, suggesting the addition of methanol only has a slight influence on the ORR process and $\mathrm{CoO}_{x}-800$ exhibits a relatively robust catalytic capability.

The cycling performance of the $\mathrm{CoO}_{x}-800$ electrode was further evaluated. As shown in Fig. S2, $\uparrow$ the CV curves of the $\mathrm{CoO}_{x}-800$ electrode in the $1^{\text {st }}, 50^{\text {th }}$, and $1000^{\text {th }}$ cycles almost overlap, suggesting its superior cyclability during the longterm ORR process.

The superior electrocatalytic property of the $\mathrm{CoO}_{x}-800$ electrode can be mainly attributed to the effective synergy of its unique structural merits in terms of structural defects, phase heterostructure and porous architecture: (1) the presence of metallic Co and graphitic carbon species can significantly enhance the electrical transport within the composite electrode, thus leading to reduced polarization and boosted ORR kinetics; (2) the coherent nanosized $\mathrm{CoO} / \mathrm{Co}_{3} \mathrm{O}_{4}$ heterostructure can further boost the electron transport at interface and propel the $\mathrm{O}_{2}$ reduction process; (3) the existence of oxygen vacancy $\left(V_{\mathrm{o}}\right)$ in $\mathrm{CoO}$ can enhance its binding energy towards $\mathrm{O}_{2}$ and lower the activation energy barrier for $\mathrm{O}_{2}$ electroreduction; (4) the porous and loose carbon framework can facilitate the electrolyte transport and diffusion of $\mathrm{O}_{2}$ and reaction intermediates. The synergetic function of the above enables the $\mathrm{CoO}_{x}-800$ electrode to deliver a superior electrocatalytic performance for ORR process.

\section{Conclusions}

In summary, we have demonstrated a facile route for synthesis of a coherent nanoscale $\mathrm{Co} / \mathrm{CoO} / \mathrm{Co}_{3} \mathrm{O}_{4}$ heterojunction encapsulated in a porous carbon framework. Benefiting from the introduction of graphitized carbon matrix and metallic Co species as well as formation of nanoscale $\mathrm{CoO} / \mathrm{Co}_{3} \mathrm{O}_{4}$ heterostructure with oxygen vacancies, the composite catalyst shows outstanding ORR catalytic activity compared to pure $\mathrm{CoO}$ and high methanol tolerance. The present strategy may be extended to the design and fabrication of other heterostructure composite electrocatalysts for electrochemical oxygen reduction and evolution processes.

\section{Conflicts of interest}

There are no conflicts to declare.

\section{Acknowledgements}

This work is funded by the National Natural Science Foundation of China (Grant No. 51302204). H.-E. Wang thanks the Hubei Provincial Department of Education for the "Chutian Scholar" program. The authors also thank Prof. Bao-Lian Su (University of Namur), Guozhong Cao (University of Washington) and Wenjun Zhang (City University of Hong Kong) for kind support. 


\section{References}

1 J. L. Liu, D. D. Zhu, C. X. Guo, A. Vasileff and S. Z. Qiao, Adv. Energy Mater., 2017, 7, 26.

2 Z. X. Yan, H. E. Wang, M. P. Zhang, Z. F. Jiang, T. S. Jiang and J. M. Xie, Electrochim. Acta, 2013, 95, 218-224.

3 Z. X. Yan, M. M. Zhang, J. M. Xie, H. E. Wang and W. Wei, J. Power Sources, 2013, 243, 48-53.

4 J. Ying, J. Li, G. P. Jiang, Z. P. Cano, Z. Ma, C. Zhong, D. Su and Z. W. Chen, Appl. Catal., B, 2018, 225, 496-503.

5 Z. X. Yan, L. N. Gao, C. J. Dai, M. M. Zhang, X. M. Lv and P. K. Shen, Int. J. Hydrogen Energy, 2018, 43, 3705-3715.

6 J. Ying, G. P. Jiang, Z. P. Cano, L. Han, X. Y. Yang and Z. W. Chen, Nano Energy, 2017, 40, 88-94.

7 (a) H. Xu, P. P. Song, F. Gao, Y. Shiraishi and Y. K. Du, Nanoscale, 2018, 10, 8246-8252; (b) J. B. Ding, L. Z. Bu, S. J. Guo, Z. P. Zhao, E. B. Zhu, Y. Huang and X. Q. Huang, Nano Lett., 2016, 16, 2762-2767; (c) L. Z. Bu, C. Y. Tang, Q. Shao, X. Zhu and X. Q. Huang, ACS Catal., 2018, 8, 4569-4575.

8 H. Xu, B. Yan, J. Wang, K. Zhang, S. M. Li, Z. P. Xiong, C. Q. Wang, Y. Shiraishi, Y. K. Du and P. Yang, J. Mater. Chem. A, 2017, 5, 15932-15939.

9 S. Wu, Y. Zhu, Y. Huo, Y. Luo, L. Zhang, Y. Wan, B. Nan, L. Cao, Z. Wang, M. Li, M. Yang, H. Cheng and Z. Lu, Sci. China Mater., 2017, 60, 654-663.

10 Y. Zhou, R. G. Ma, S. L. Candelaria, J. C. Wang, Q. Liu, E. Uchaker, P. X. Li, Y. F. Chen and G. Z. Cao, J. Power Sources, 2016, 314, 39-48.

11 R. G. Ma, Y. Zhou, P. X. Li, Y. F. Chen, J. C. Wang and Q. Liu, Electrochim. Acta, 2016, 216, 347-354.

12 R. G. Ma, B. Y. Xia, Y. Zhou, P. X. Li, Y. F. Chen, Q. Liu and J. C. Wang, Carbon, 2016, 102, 58-65.

13 R. G. Ma, X. D. Ren, B. Y. Xia, Y. Zhou, C. Sun, Q. Liu, J. J. Liu and J. C. Wang, Nano Res., 2016, 9, 808-819.

14 R. G. Ma, X. D. Ren, B. Y. Xia, Y. Zhou, C. Sun, Q. Liu, J. J. Liu and J. C. Wang, Nano Res., 2017, 10, 2332-2343.

15 Q. C. Wang, Z. Y. Chen, N. Wu, B. Wang, W. He, Y. P. Lei and Y. D. Wang, ChemElectroChem, 2017, 4, 514-520.

16 Y. P. Lei, Q. Shi, C. Han, B. Wang, N. Wu, H. Wang and Y. D. Wang, Nano Res., 2016, 9, 2498-2509.

17 C. Q. Shang, M. C. Li, Z. Y. Wang, S. F. Wu and Z. G. Lu, ChemElectroChem, 2016, 3, 1437-1445.

18 R. Li, X. Z. Wang, Y. F. Dong, X. Pan, X. G. Liu, Z. B. Zhao and J. S. Qiu, Carbon, 2018, 132, 580-588.

19 Y. Y. Liang, Y. G. Li, H. L. Wang, J. G. Zhou, J. Wang, T. Regier and H. J. Dai, Nat. Mater., 2011, 10, 780-786.

20 (a) X. Han, G. He, Y. He, J. Zhang, X. Zheng, L. Li, C. Zhong, W. Hu, Y. Deng and T.-Y. Ma, Adv. Energy Mater., 2018, 1702222; (b) H. Lee, J. Lim, C. Lee, S. Back, K. An, J. W. Shin, R. Ryoo, Y. Jung and J. Y. Park, Nat. Commun., 2018, 9, 2235.

21 B. Y. Li, Y. H. Zhang, R. F. Du, L. Liu and X. L. Yu, Nanotechnology, 2018, 29, 8.
22 Q. S. Huang, P. J. Zhou, H. Yang, L. L. Zhu and H. Y. Wu, Electrochim. Acta, 2017, 232, 339-347.

23 S. J. Guo, S. Zhang, L. H. Wu and S. H. Sun, Angew. Chem., Int. Ed., 2012, 51, 11770-11773.

24 Y. Liu, Y. Liu, S. H.-S. Cheng, S. Yu, B. Nan, H. Bian, K. Md, M. Wang, C. Y. Chung and Z.-G. Lu, Electrochim. Acta, 2016, 219, 560-567.

25 X. Zhang, R. R. Liu, Y. P. Zang, G. Q. Liu, G. Z. Wang, Y. X. Zhang, H. M. Zhang and H. J. Zhao, Chem. Commun., 2016, 52, 5946-5949.

26 C. D. Bai, S. S. Wei, D. R. Deng, X. D. Lin, M. S. Zheng and Q. F. Dong, J. Mater. Chem. A, 2017, 5, 9533-9536.

27 Z. Zeng, T. Zhang, Y. Y. Liu, W. D. Zhang, Z. Y. Yin, Z. W. Ji and J. J. Wei, ChemSusChem, 2018, 11, 580-588.

28 I. A. Khan, A. Badshah and M. A. Nadeem, Catal. Commun., 2017, 99, 10-14.

29 H. Kim, Y. Kim, Y. Noh, S. Lee, J. Sung and W. B. Kim, ChemCatChem, 2017, 9, 1503-1510.

30 J. Li, Q. F. Wang, K. Liu, J. B. Jiang, D. Qian, J. H. Li and Z. H. Chen, Mater. Lett., 2017, 186, 189-192.

31 M. Liu, J. J. Liu, Z. L. Li and F. Wang, ACS Appl. Mater. Interfaces, 2018, 10, 7052-7060.

32 L. Lv, D. Zha, Y. Ruan, Z. Li, X. Ao, J. Zheng, J. Jiang, H. M. Chen, W.-H. Chiang, J. Chen and C. Wang, ACS Nano, 2018, 12, 3042-3051.

33 X. F. Zheng, G. F. Shen, Y. Li, H. N. Duan, X. Y. Yang, S. Z. Huang, H. E. Wang, C. Wang, Z. Deng and B. L. Su, J. Mater. Chem. A, 2013, 1, 1394-1400.

34 V. G. Hadjiev, M. N. Iliev and I. V. Vergilov, J. Phys. C: Solid State Phys., 1988, 21, L199-L201.

35 (a) R. Gao, Z. Y. Li, X. L. Zhang, J. C. Zhang, Z. B. Hu and X. F. Liu, ACS Catal., 2016, 6, 400-406; (b) C. Y. Zhao, Y. Cai, K. L. Yin, H. Z. Li, D. Shen, N. Qin, Z. G. Lu, C. P. Liu and H. E. Wang, Chem. Eng. J., 2018, 350, 201-208.

36 R. Gao, L. Liu, Z. B. Hu, P. Zhang, X. Z. Cao, B. Y. Wang and X. F. Liu, J. Mater. Chem. A, 2015, 3, 17598-17605.

37 H. E. Wang, X. Zhao, X. C. Li, Z. Y. Wang, C. F. Liu, Z. G. Lu, W. J. Zhang and G. Z. Cao, J. Mater. Chem. A, 2017, 5, 2505625063.

38 H. K. Wang, X. M. Yang, Q. Z. Wu, Q. B. Zhang, H. X. Chen, H. M. Jing, J. K. Wang, S. B. Mi, A. L. Rogach and C. M. Niu, ACS Nano, 2018, 12, 3406-3416.

39 T. Liu, Y. F. Guo, Y. M. Yan, F. Wang, C. Deng, D. Rooney and K. N. Sun, Carbon, 2016, 106, 84-92.

40 H. E. Wang, X. Zhao, K. L. Yin, Y. Li, L. H. Chen, X. Y. Yang, W. J. Zhang, B. L. Su and G. Z. Cao, ACS Appl. Mater. Interfaces, 2017, 9, 43665-43673.

41 Y. Cai, H. E. Wang, X. Zhao, F. Huang, C. Wang, Z. Deng, Y. Li, G. Z. Cao and B. L. Su, ACS Appl. Mater. Interfaces, 2017, 9, 10652-10663.

42 B. Y. Xia, Y. Yan, N. Li, H. B. Wu, X. W. Lou and X. Wang, Nat. Energy, 2016, 1, 15006.

43 S. Gadipelli, T. T. Zhao, S. A. Shevlin and Z. X. Guo, Energy Environ. Sci., 2016, 9, 1661-1667. 